\title{
Museus escolares: uma análise das produções em programas de pós-graduação
}

\author{
School museums: an analysis of productions in postgraduate programs \\ Museos escolares: un análisis de las producciones en los programas de posgrado
}

Recebido: 23/09/2021 | Revisado: 28/09/2021 | Aceito: 29/09/2021 | Publicado: 30/09/2021

\author{
Adriana Conti Rezende \\ ORCID: https://orcid.org/0000-0002-2830-8459 \\ Instituto Superior de Educação do Rio de Janeiro, Brasil \\ E-mail: adriconti gmail.com \\ Eline Deccache-Maia \\ ORCID: https://orcid.org/0000-0003-4770-3988 \\ Instituto Federal de Educação, Ciência e Tecnologia do Rio de Janeiro, Brasil \\ E-mail: eline.maia@ifrj.edu.br
}

\begin{abstract}
Resumo
O presente trabalho teve como objetivo analisar as produções acadêmicas a respeito dos museus escolares, buscando entender o seu papel na educação brasileira e traçar um panorama sobre o tema. Museus escolares surgem como espaços de aplicação do método de ensino intuitivo, bastante disseminado na primeira metade do século XX. São considerados espaços de ensino, de aplicação de novas metodologias pedagógicas, de formação de professores e de memória escolar. Dividem-se em museus e gabinetes de história natural, museus pedagógicos, museus da memória escolar, incluindo em seu acervo objetos de memória e/ou recursos pedagógicos. O período que vai do início do século XX até a década de 1940 marca a fase mais promissora dos museus escolares, quando muitos deles foram implantados. Os museus escolares ainda existentes carecem de maior compreensão do seu papel no ensino atual, em especial no ensino de ciências.
\end{abstract}

Palavras-chave: Museus escolares; Produções acadêmicas; Ensino de ciências; Memória.

\begin{abstract}
The current work aimed to analyze the academic productions about school museums, in order to understand their role in Brazilian education and to draw an overview of the theme. School museums are spaces for the application of the intuitive teaching method, widespread in the first half of the 20th century. They are considered spaces for teaching, for application of new pedagogical methodologies, teacher training and school memory. They are divided into museums and offices of natural history, pedagogical museums, museums of school memory, including in their collection objects of memory and pedagogical resources. The period from the beginning of the twentieth century to the 1940s marks the most promising phase for this type of school institution. Its role in current education needs more foundation, especially in science teaching.
\end{abstract}

Keywords: School museum; Academic productions; Science teaching; Memory.

\section{Resumen}

El presente trabajo tuvo como objetivo analizar las producciones académicas sobre los museos escolares, buscando comprender su papel en la educación brasileña y esbozar una visión general del tema. Los museos escolares aparecen como espacios para la aplicación del método de enseñanza intuitivo, ampliamente difundido en la primera mitad del siglo XX. Se consideran espacios para la docencia, la aplicación de nuevas metodologías pedagógicas, la formación del profesorado y la memoria escolar. Se dividen en museos y oficinas de historia natural, museos pedagógicos, museos de memoria escolar, que incluyen objetos de memoria y / o recursos pedagógicos en su colección. El período comprendido entre principios del siglo XX y la década de 1940 marca la fase más prometedora de los museos escolares, cuando se establecieron muchos de ellos. Los museos escolares aún existentes carecen de una mayor comprensión de su papel en la educación actual, especialmente en la educación científica.

Palabras clave: Museos escolares; Producciones acadêmicas; Enseñanza de la ciência; Memoria.

\section{Introdução}

Museus são espaços democratizantes e de diálogo (ICOM, 2019), fontes importantes de conhecimento e de divulgação científica e que podem ser utilizados como instrumentos de aprendizagem.

São muitos os formatos existentes de museus hoje em dia, derivados de um longo processo histórico. Em um universo de instituições museológicas, os museus escolares se apresentam como uma categoria pouco conhecida. Museus escolares 
estão vinculados às instituições formais de ensino tendo como finalidade a divulgação de novas metodologias de ensino, a formação de professores e renovação de práticas de aprendizado nas escolas normais, bem como a salvaguarda do patrimônio e da memória escolar (Poggiani, 2011). São incluídos nessa terminologia os acervos, museus, memoriais e centros de memória (Alves, 2016). A definição dos museus escolares é complexa e polissêmica, dependendo do contexto em que está inserido (Petry \& Silva, 2013), podendo ser apresentados de múltiplas formas: museus para guarda de objetos em armários, coleção de quadros parietais, gabinetes e espaços em salas de aula (Silva, 2015).

Tomando como referência o Brasil, esta categoria de museus surgiu no final do século XIX como uma forma de atender às diretrizes da metodologia de ensino intuitivo e da Lição das Coisas, cujo objetivo era tornar o ensino mais concreto (Schelbauer, 2005). Ganham notoriedade no século XX, entre as décadas de 1920 e 1940, sendo esta última década marcada pelo surgimento de uma quantidade significativa desses espaços no Brasil.

Alguns trabalhos destacam a relevância dos museus escolares na história da educação brasileira (VIDAL, 1999; Peixoto, 2004; Bastos, 2005; Petry \& Silva, 2013; Silva, 2015; Alves, 2016; Possamai \& Paz, 2017; Rezende \& DeccacheMaia, 2020). Entretanto, ainda são poucos os estudos que abordam uma visão global sobre os museus escolares no Brasil.

Pelo exposto, o nosso objetivo é avançar um pouco mais no entendimento do que vem a ser os museus escolares no Brasil, olhando as produções de pesquisas existentes, visando construir um panorama a respeito do tema, bem como indicar frentes de pesquisa.

\section{Metodologia}

Nossa pesquisa tem cunho qualitativo, descritivo e bibliográfica. Esses dois últimos escolhidos por se tratar de uma aproximação com o tema já identificado como pouco estudado, cujos resultados alcançados ensejarão pesquisas futuras. Em relação ao caráter bibliográfico da pesquisa, é preciso fazer uma ressalva para que não se confunda esse formato com a revisão bibliográfica que antecede toda e qualquer pesquisa. Segundo Lima \& Mioto (2007, p. 44)

Ao tratar da pesquisa bibliográfica, é importante destacar que ela é sempre realizada para fundamentar teoricamente o objeto de estudo, contribuindo com elementos que subsidiam a análise futura dos dados obtidos. Portanto, difere da revisão bibliográfica uma vez que vai além da simples observação de dados contidos nas fontes pesquisadas, pois imprime sobre eles a teoria, a compreensão crítica do significado neles existente.

Para dar conta do nosso intento, privilegiamos como fonte de dados as produções acadêmicas realizadas no âmbito dos programas de pós-graduação nacionais, por já terem passado por avaliações e por acreditarmos que derivam daí produções com rigor metodológico e, geralmente, feitas a partir de grupos de pesquisa já constituídos. Nesse sentido, a plataforma CAPES se destacou como ambiente propício para o acesso de Teses e Dissertações sobre a temática, tendo sido usado como descritores os termos "museu escolar" e "museus escolares". A primeira consulta à plataforma para levantamento dos títulos sobre o tema foi realizada no final de 2020 e atualizada em setembro de 2021.

\section{Resultados e Discussão}

As consultas à plataforma CAPES utilizando os dois descritores entre aspas, resultaram ao todo em 29 trabalhos. Dos 29 títulos encontrados inicialmente, 15 foram obtidos usando o descritor "museu escolar" e 14 usando "museus escolares". Em uma primeira leitura exploratória, descartamos repetições e trabalhos que não abordavam o tema museu escolar, ou que quando o faziam era de forma tangencial, sem expressão para o nosso estudo. Portanto, dos 15 trabalhos obtidos com a busca do termo no singular, descartamos 5 por identificarmos que eles abordavam tangencialmente a temática, fazendo com que tivéssemos 10 títulos para análise. Com o uso do descritor no plural obtivemos 14 trabalhos, destes, 3 não abordavam o tema diretamente e 6 
já haviam aparecido na primeira consulta, restando apenas 5 que somados à busca anterior perfez um total de 15 títulos, expostos no Quadro 1 que se segue:

Quadro 1 - Dissertações e teses sobre Museus Escolares.

\begin{tabular}{|c|c|c|c|c|}
\hline Nome & Título & Tipo & Instituição & Ano \\
\hline $\begin{array}{l}\text { 1. POGGIANI, Ana } \\
\text { Maria Lourenço }\end{array}$ & $\begin{array}{l}\text { Os museus escolares na primeira metade do } \\
\text { século XX: sua importância na Educação } \\
\text { Brasileira }\end{array}$ & Dissertação & UniSantos & 2011 \\
\hline $\begin{array}{l}\text { 2. SCHLICKMANN, } \\
\text { Karina Santos } \\
\text { Vieira }\end{array}$ & $\begin{array}{l}\text { Museus Irmão Luiz Gartiner: um percurso de } \\
\text { investigação no acervo taxidermizado de aves e } \\
\text { de mamíferos (Corupá/SC - 1932-1953) }\end{array}$ & Dissertação & UDESC & 2011 \\
\hline $\begin{array}{l}\text { 3. BORCIONI, } \\
\text { Leonardo }\end{array}$ & $\begin{array}{l}\text { O museu escolar do CEAP: reflexões sobre a } \\
\text { prática museal e a relação entre memória e } \\
\text { história }\end{array}$ & Dissertação & UFSM-RS & 2012 \\
\hline $\begin{array}{l}\text { 4. } \begin{array}{l}\text { BOCCHI, Luna } \\
\text { Abrano }\end{array} \\
\end{array}$ & $\begin{array}{l}\text { A configuração de novos locais e práticas } \\
\text { pedagógicas na escola: o museu escolar, os } \\
\text { laboratórios e gabinetes de ensino do Colégio } \\
\text { Marista Arquidiocesano de São Paulo (1908- } \\
\text { 1940) }\end{array}$ & Dissertação & PUC-SP & 2013 \\
\hline $\begin{array}{l}\text { 5. PETRY, Marilia } \\
\text { Gabriela }\end{array}$ & $\begin{array}{l}\text { Da recolha à exposição: a constituição de } \\
\text { museus escolares em escolas públicas primárias } \\
\text { de Santa Catarina (Brasil - 1911-1952) }\end{array}$ & Dissertação & UDESC & 2013 \\
\hline $\begin{array}{l}\text { 6. SANTOS, Debora } \\
\text { Pereira dos }\end{array}$ & $\begin{array}{l}\text { Prática(s) de Ensino na Escola Normal Padre } \\
\text { Anchieta na década de 1930: o museu } \\
\text { didático nas proposições da Professora } \\
\text { Leontina Silva Busch }\end{array}$ & Dissertação & USP & 2014 \\
\hline $\begin{array}{l}\text { 7. PAZ, Felipe } \\
\text { Rodrigo Contri }\end{array}$ & 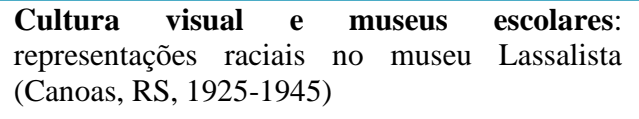 & Dissertação & UFRGS & 2015 \\
\hline $\begin{array}{l}\text { 8. SILVA, Camila } \\
\text { Marchi da }\end{array}$ & $\begin{array}{l}\text { Museus escolares no Estado de São Paulo } \\
(1879-1942)\end{array}$ & Dissertação & PUC-SP & 2015 \\
\hline $\begin{array}{lr}\text { 9. } & \text { RIBEIRO, } \\
\text { Quiteria } & \text { Lucia } \\
\text { Ferreira } & \text { de } \\
\text { Alencar } & \end{array}$ & $\begin{array}{l}\text { Escola normal rural de Juazeiro do Norte: do } \\
\text { Museu Vilas Nova Portugal à Sala de Memória } \\
\text { Amália Xavier De Oliveira }\end{array}$ & Dissertação & UFC & 2015 \\
\hline $\begin{array}{l}\text { 10. OLIVEIRA, } \\
\text { Fabiana Valeck de }\end{array}$ & $\begin{array}{l}\text { Patrimônio escolar: para além da arquitetura, a } \\
\text { materialidade do patrimônio histórico nas } \\
\text { escolas paulistas }\end{array}$ & Tese & USP & 2015 \\
\hline $\begin{array}{l}\text { 11. WITT, } \\
\text { Beatriz }\end{array}$ & $\begin{array}{l}\text { Uma Joia" no Sul do Brasil, O Museu de } \\
\text { História Natural do Colégio Anchieta: } \\
\text { pesquisa científica e ensino em uma escola } \\
\text { jesuíta nas primeiras décadas do século XX } \\
\text { (PortoAlegre/RS) }\end{array}$ & Dissertação & UFRGS & 2016 \\
\hline $\begin{array}{l}\text { 12. MARQUES, } \\
\text { Mirian Ramos }\end{array}$ & $\begin{array}{l}\text { Cultura material escolar, patrimônio e } \\
\text { tecnologias: os objetos de ensino do ginásio } \\
\text { São José da lapa - Paraná (1949-1981) }\end{array}$ & Dissertação & UNINTER & 2016 \\
\hline $\begin{array}{l}\text { 13. SELANO, Alyne } \\
\text { Mendes Fabro }\end{array}$ & $\begin{array}{l}\text { O museu escolar e reflexões históricas: usos e } \\
\text { apropriações da memória do Instituto de } \\
\text { Educação Governador Roberto Silveira }\end{array}$ & Dissertação & UERJ & 2016 \\
\hline $\begin{array}{l}\text { 14. ALVES, Vania } \\
\text { Maria Siqueira }\end{array}$ & $\begin{array}{l}\text { Museus Escolares: de recurso de ensino ao } \\
\text { patrimônio e a Museologia }\end{array}$ & Tese & UNIRIO & 2016 \\
\hline $\begin{array}{l}\text { 15. JOSE, Vivian } \\
\text { Alkaim Salomão }\end{array}$ & $\begin{array}{l}\text { Educação patrimonial e o ensino de história } \\
\text { na cidade de Santa Maria - RS }\end{array}$ & Dissertação & UFSM-RS & 2020 \\
\hline
\end{tabular}


Desses 15 trabalhos, 10 foram desenvolvidos em Programas de Pós-Graduação na área de Educação, os demais estão distribuídos pelas áreas de Arquitetura e Urbanismo, Museologia e Patrimônio, Patrimônio Cultural, Ciências Sociais e Ensino de História, sendo um em cada uma dessas áreas de conhecimento.

As pesquisas levantadas também se concentram na região Sudeste e Sul do Brasil. O estado de SP e RS foram os que mais apresentaram interesse no tema, totalizando 5 e 4 trabalhos respectivamente cada, seguido de SC e RJ com 2 estudos cada e PR com apenas 1. Houve apenas uma pesquisa na região Nordeste (CE). A ausência e/ou baixa incidência de estudos nas demais regiões e estados no Brasil podem ser decorrentes da inexistência dessas instituições nesses locais, algo a ser investigado em pesquisas futuras. Dentre os trabalhos levantados, apenas dois desenvolvem a temática dos museus escolares num contexto nacional, o de Poggiani (2011) e o de Alves, (2016). Poggiani (2011) discute sua importância na educação brasileira desde a criação dessas instituições, no final do século XIX, até a primeira metade do século XX. Alves (2016) aborda aspectos dos museus escolares em funcionamento no Brasil. Em âmbito regional, Petry (2013) faz um recorte dos museus escolares nas escolas públicas primárias de Santa Catarina (1919-1952), Silva (2015) no Estado de São Paulo (1879-1942) e Oliveira (2015) nas primeiras Escolas Normais implantadas no Estado de São Paulo.

A maior parte das pesquisas levantadas situam os museus escolares e os espaços de memória histórica, a partir de estudos de caso (Schlickmann, 2011; Bocchi, 2013; Santos, 2013; Borcioni, 2012; paz, 2015; Ribeiro, 2015; Marques, 2016; Selano, 2016; Witt, 2016 e José, 2020), procurando discutir a sua inserção pedagógica nas instituições às quais pertenciam.

Ao analisar as palavras-chave contidas nesses estudos (Quadro 2), foram encontrados os seguintes termos por ordem de relevância:

Quadro 2 - Palavras-chave mais frequentes.

\begin{tabular}{|lc|}
\hline \multicolumn{1}{|c|}{ Palavra-chave } & Ocorrência \\
\hline Museu escolar & 10 \\
\hline Cultura material escolar & 3 \\
\hline Museu pedagógico & 2 \\
\hline Método intuitivo & 2 \\
\hline Prática de ensino & 2 \\
\hline Memória & 2 \\
\hline História, & 2 \\
\hline Patrimônio Cultural & 2 \\
\hline Museologia & 2 \\
\hline Educação patrimonial & 2 \\
\hline $\begin{array}{l}\text { Patrimônio histórico, patrimônio escolar, } \\
\text { preservação de patrimônio, preservação do } \\
\text { patrimônio, história da educação, história dos } \\
\text { museus escolares, memória coletiva, memória } \\
\text { escolar }\end{array}$ & 1 \\
\hline
\end{tabular}

Fonte: Autores.

Tais resultados sugerem que a temática dos museus escolares aparece mais relacionada tanto à área de Educação e História da Educação, quanto à área de Museologia e Patrimônio. Apesar de tradicionalmente voltados para o ensino de ciências e de história natural, principalmente nas primeiras décadas do século XX (Paz, 2015), as palavras-chave "museu de história natural", "ciências naturais" e "ensino de ciências" só aparecem uma vez cada, demonstrando que foram poucos os trabalhos de pesquisa realizados com enfoque no papel desses museus no ensino de ciências propriamente dito.

O termo cultura material escolar aparece em segundo lugar (Petry, 2013; Silva, 2015 e Marques, 2016). Aqui se compreende o termo cultura material escolar como sendo o conjunto de objetos, materiais didáticos, mobiliários e bases arquitetônicas, parte integrante dessa memória institucional (Schlickmann, 2011). O termo cultura material escolar também 
pode ser usado para designar, além dos objetos, os espaços de memória. A cultura escolar, por sua vez, é considerada como um conjunto de práticas, normas, ritos, disciplinas e representações, que têm como um dos principais elementos a cultura material escolar (Marques, 2016).

Poggiani (2011), Silva (2015) e Paz (2015) trazem contribuições dos museus escolares na aplicação do método intuitivo ou Lições de Coisas. Tal metodologia foi bastante disseminada nas escolas primárias e secundárias no Brasil no início do século XX, com forte ligação com os ideais positivistas e republicanos (Paz, 2015; Bocchi, 2013).

A análise do material levantado por esta pesquisa permitiu, ainda, estabelecer algumas categorias: museus escolares da passagem do século XIX para XX; museus escolares da primeira metade do século XX; museus escolares da segunda metade do século XX até a atualidade; museus de história natural; museus pedagógicos e museus históricos (onde predominava a memória escolar, institucional) como os institutos de memória e salas de memória. Tal distribuição pode ser melhor visualizada no Quadro 3.

Quadro 3 - Museus de História Natural, Museus Históricos e Museus pedagógicos por período estudado.

\begin{tabular}{|c|c|c|c|}
\hline Período estudado & $\begin{array}{l}\text { Museus de História } \\
\text { Natural (museus de } \\
\text { ciências, gabinetes etc.) }\end{array}$ & $\begin{array}{l}\text { Museus Históricos (salas } \\
\text { de memória, centros de } \\
\text { memória, memoriais) }\end{array}$ & Museus Pedagógicos \\
\hline Final do Séc. XIX & $\begin{array}{l}\text { POGGIANI (2011), } \\
\text { MARCHI (2015) e } \\
\text { OLIVEIRA (2015) }\end{array}$ & & $\begin{array}{l}\text { POGGIANI (2011) e } \\
\text { MARCHI (2015) }\end{array}$ \\
\hline $1^{a}$ metade do Séc. $X X$ & $\begin{array}{l}\text { SCHLICKMANN (2011), } \\
\text { BOCCHI (2013), PETRY } \\
(2013), \quad \text { PAZ (2015), } \\
\text { RIBEIRO (2015), WITT } \\
(2016)\end{array}$ & $\begin{array}{l}\text { DALPIAZ (2005), } \\
\text { SANTOS (2013) }\end{array}$ & \\
\hline $2^{\mathrm{a}}$ metade do Séc. $\mathrm{XX}$ & ALVES (2016) & $\begin{array}{l}\text { POGGIANI (2011), } \\
\text { BORCIONI (2012), } \\
\text { RIBEIRO (2015), } \\
\text { ALVES (2016), } \\
\text { MARQUES (2016), } \\
\text { SELANO (2016) e JOSÉ } \\
(2020)\end{array}$ & \\
\hline
\end{tabular}

Fonte: Autores.

\section{Museus de História Natural}

Quando o assunto é museu escolar uma das principais referências é Leontina Brusch, professora da Escola Normal Padre Anchieta, São Paulo (Santos, 2013; Poggiani, 2011), cujas contribuições foram de grande valia para a construção e organização de museus escolares. Em Santos (2013), os museus didáticos são apontados como importantes marcos na reestruturação da prática nas Escolas Normais de São Paulo na década de 1930. Estes espaços eram constituídos de materiais pedagógicos confeccionados pelas próprias professoras e normalistas e utilizados nas aulas da educação primária.

Alves (2016) classifica os museus escolares em museus de ciências - anteriores a 1970 e que compreendiam as coleções e recursos de ensino; e museus históricos - criados após 1970, cujo objetivo é a salvaguarda da memória institucional. Já os museus pedagógicos eram considerados centros de formação para professores, onde eram difundidas novas metodologias e instrumentos didáticos (Petry e Silva, 2013). Witt (2016) em seu estudo distingue três tipologias de museus de educação: os museus escolares, os museus pedagógicos e os museus de história natural, atrelando os dois primeiros tipos ao ensino, aplicação do método intuitivo e Lições das Coisas, e o terceiro à pesquisa. Poggiani (2011) em seu trabalho chegou a três denominações para os museus escolares: os Museus de História Natural, voltados exclusivamente para o ensino de ciências, os 
Museus Escolares, considerados renovadores do ensino, absorvendo em grande parte os de História Natural e os Museus Pedagógicos, cujo objetivo era o de aperfeiçoar e atualizar os professores.

Schlickmann (2011) descreve com detalhes o acervo de animais taxidermizados do museu de história natural Irmão Luiz Gartner, localizado no Seminário Sagrado Coração de Jesus (Corupá, SC), questionando sua relevância pedagógica para o ensino de ciências.

A análise dos resultados das pesquisas que realizaram estudos de casos permitiu observar que a maior parte dos museus escolares na primeira metade do século XX, era voltada para o ensino de ciências, como no caso do museu escolar do Colégio Marista Arquidiocesano, SP (Poggiani, 2011, Bocchi, 2013 e Marchi, 2015), o Museu de História Natural e Pedagógico do Colégio São José (Poggiani, 2011), o Museu de História Natural de Escola Normal (Silva, 2013), o Museu Irmão Luiz Gartner (Schlickmann, 2011), o Museu do Instituto São José (Paz, 2015), o Museu Vilas Nova de Portugal (RIBEIRO, 2015), o Museu de História Natural da Escola Normal Caetano de Campos (Oliveira, 2015) e o Museu de História Natural do Colégio Anchieta (Witt, 2016). Já na segunda metade do século XX, predominaram os museus históricos, voltados para a salvaguarda da memória escolar como pode ser conferido no Quadro 4.

Quadro 4 - Tipos de acervo dos Museus Escolares.

\begin{tabular}{|c|c|c|c|}
\hline $\begin{array}{l}\text { Nome da instituição /tese ou } \\
\text { dissertação }\end{array}$ & Localização & Nome do museu escolar & de acervo \\
\hline $\begin{array}{l}\text { Instituto de Educação } \\
\text { Governador Roberto Silveira } \\
\text { (SELANO, 2016) }\end{array}$ & Duque de Caxias, RJ & Instituto Histórico do IEGRS & Memória escolar \\
\hline $\begin{array}{l}\text { Escola Normal Rural Juazeiro do } \\
\text { Norte } \\
\text { (RIBEIRO, 2015) }\end{array}$ & Juazeiro do Norte, CE & $\begin{array}{l}\text { Sala de Memória Amália Xavier de } \\
\text { Oliveira e Museu Villas Novas } \\
\text { Portugal* }\end{array}$ & $\begin{array}{l}\text { Memória escolar } \\
\text { História Natural* }\end{array}$ \\
\hline $\begin{array}{l}\text { Escola Normal Caetano de } \\
\text { Campos } \\
\text { USP } \\
\text { (OLIVEIRA, 2015) }\end{array}$ & São Paulo, SP & $\begin{array}{l}\text { Museu Caetano de Campos } \\
\text { Centro de Referência em Educação } \\
\text { Mario Covas }\end{array}$ & $\begin{array}{l}\text { Museu Pedagógico e de } \\
\text { História Natural } \\
\text { Memória Escolar }\end{array}$ \\
\hline $\begin{array}{l}\text { Colégio Marista Arquidiocesano } \\
\text { (POGGIANI, 2011; BOCHI, } \\
\text { 2013) }\end{array}$ & São Paulo, SP & Gabinete de História Natural & História Natural \\
\hline Colégio Anchieta (WITT, 2016)** & Porto Alegre, RS & $\begin{array}{l}\text { Museu de História Natural do Colégio } \\
\text { Anchieta }\end{array}$ & História Natural \\
\hline $\begin{array}{l}\text { Escola Normal Padre Anchieta } \\
\text { (SANTOS, 2013) }\end{array}$ & São Paulo, SP & $\begin{array}{l}\text { Museu Didático da Escola Normal } \\
\text { Padre Anchieta }\end{array}$ & Museu Pedagógico \\
\hline $\begin{array}{l}\text { Ginásio S.J. da Lapa } \\
\text { (MARQUES, 2016) }\end{array}$ & São José da Lapa, PR & & Memória Escolar \\
\hline $\begin{array}{l}\text { Instituto de Educação de Minas } \\
\text { Gerais } \\
\text { (POGGIANI, 2011) }\end{array}$ & MG & Museu da Escola de Minas Gerais & Memória Escolar \\
\hline $\begin{array}{l}\text { Escola Apostólica Sagrado } \\
\text { Coração de Jesus } \\
\text { (SCHLICKMANN, 2011) }\end{array}$ & Corupá, SC & Museu Luiz Gardtner & História Natural \\
\hline $\begin{array}{l}\text { Colégio Evangélico Augusto } \\
\text { Pestana (BORCIONI, 2012) }\end{array}$ & Ijuí, RS & Museu Escola do CEAP & Memória Escolar \\
\hline $\begin{array}{l}\text { Instituto de Educação Olavo } \\
\text { Bilac } \\
\text { (JOSÉ, 2020) }\end{array}$ & Santa Maria, RS & $\begin{array}{l}\text { Memorial do Instituto de Educação } \\
\text { Olavo Bilac }\end{array}$ & Memória Escolar \\
\hline $\begin{array}{l}\text { Colégio Manoel Ribas } \\
\text { (JOSÉ, 2020) }\end{array}$ & Santa Maria, RS & Memorial do Colégio Manoel Ribas & Memória Escolar \\
\hline $\begin{array}{l}\text { Instituto São José } \\
\text { (PAZ, 2015) }\end{array}$ & Canoas, RS & Museu Escolar*** & $\begin{array}{l}\text { História, Geografia e } \\
\text { História natural }\end{array}$ \\
\hline
\end{tabular}

*atualmente o acervo de história natural do Museu Villas Nova Portugal se encontra no Museu Padre Cícero, Juazeiro do Norte, CE. ** analisa os museus escolares em Porto Alegre classificando como museus de ciências e museus de história (WITT, 2013).

***o acervo do museu escolar do Instituto São José circulava pela escola em diferentes espaços, que recebiam diferentes denominações como sala de história natural, sala de história ou laboratório de acordo com a sua finalidade.

Fonte: Autores. 
Antes de tudo, é importante frisar que os museus que constam listados na tabela acima se referem aos que foram objeto de análise das teses e dissertações que realizaram estudos de casos. As pesquisas que fizeram estudos dos museus escolares de modo mais abrangentes ampliaram a lista trazendo outros museus escolares que têm natureza similar aos apresentados na tabela, como é o caso do Museu de História Natural do Instituto Superior de Educação do Rio de Janeiro (MHNISERJ) e do Centro de Memória da Educação Brasileira (CMEB), ambos situados no Instituto Superior de Educação do Rio de Janeiro, RJ, do Acervo do Colégio Militar do Rio de Janeiro, RJ, e do Museu de Etnologia Indígena e de História Natural da Academia, situado no Colégio Cristo Redentor - Academia de Comércio, Juiz de Fora, MG entre outros (Alves, 2016).

Os museus escolares e os museus pedagógicos, assim como os gabinetes de história natural, predominantes na primeira metade do século XX tinham como objetivo aplicação de metodologias inovadoras de ensino e possuíam em sua maioria acervos de história natural. Compreende-se aqui o acervo de história natural aquele composto de objetos voltados para o ensino de ciências, como animais taxidermizados, esqueletos, rochas, modelos que podiam ser manuseados, pranchas murais, ou seja, materiais que possibilitavam o ensino concreto, dentro da perspectiva do método intuitivo ou Lições de Coisas. Já os memoriais, salas de memória, centros de memória preconizavam a preservação da memória escolar e da história da educação, possuindo como acervo objetos ligados à cultura escolar, como mobiliário, documentos, fotos, livros e uniformes.

Os museus escolares se apresentaram, portanto, como uma importante ferramenta para implementar ações pedagógicas voltadas para o ensino de história, sendo considerados uma tipologia que conta a história da instituição escolar. Nesse sentido, os trabalhos de Ribeiro (2015), Selano (2016) e José (2020) abordam os museus escolares voltados à construção da memória da comunidade escolar.

A pesquisa realizada por José (2020) demonstra a importância dos museus escolares na construção da identidade e da memória patrimonial da cidade de Santa Maria (RS), o Memorial do Instituto de Educação Olavo Bilac, criado em 1998, e o Memorial do Colégio Manoel Ribas, criado em 2000, ambos por ocasião do tombamento arquitetônico das respectivas instituições.

Selano (2016), por sua vez, discute também o papel dos espaços de memória escolar no cotidiano escolar a partir da atuação dos discentes na construção de exposições sobre memória. Já a transição da aplicabilidade dos museus escolares pode ser observada no trabalho de Ribeiro (2015) ao comparar uma Sala de Memória construída em 2007 ao museu escolar criado nas primeiras décadas do século XX, ambos pertencentes à Escola Normal Rural de Juazeiro do Norte. Se antes o museu escolar era voltado para o ensino de ciências, com um acervo de história natural, a sala de memória preconiza a preservação da história da educação.

Entre 1911 e 1952 observa-se, portanto, uma mudança gradativa do papel dos museus escolares, que tinham inicialmente o objetivo de servir de estratégia metodológica nas lições concretas, com a instalação de gabinetes para armazenamento de peças que faziam parte do acervo material e que passam, a partir da década de 30, a fazer parte da estrutura das escolas como instituição auxiliar. Nos anos 40 , esses espaços passam a ser constituídos através de ações de professores e alunos, tornando-se um meio facilitador de ensino-aprendizagem (Petry, 2013).

\section{Considerações Finais}

Os museus escolares podem ser classificados de diferentes maneiras dependendo dos objetivos e da natureza do seu acervo. Foram encontrados ao menos três tipos: os museus de história natural, os museus pedagógicos e os museus históricos. Dividem-se de acordo com o período histórico de criação e atuação entre os museus escolares do final do século XIX, da primeira metade do século XX e da segunda metade do século XX até os dias atuais.

A manutenção desses espaços ainda hoje nas instituições escolares permite a preservação da memória e da história da 
educação, contribuindo para a construção da identidade dessas instituições e da comunidade escolar, ultrapassando por muitas vezes os muros da escola.

O presente artigo demonstra que são poucos os trabalhos que discutem as contribuições dos museus escolares para o ensino na atualidade. Uma vez que há uma ocorrência significativa de museus de história natural e de ciências nas escolas ainda hoje, seria importante que mais pesquisas abordassem o assunto dando insumos para uma discussão mais profunda a respeito do papel atual desses acervos no ensino de ciências.

O estudo aqui realizado das produções acadêmicas sobre museus escolares, no seu formato de teses e dissertações, permitiu verificar os interesses e enfoques sobre o tema e trouxe muitas indagações que carecem de aprofundamentos e novos estudos. Saber o papel dos museus escolares nos dias atuais seria um dos aspectos para estudos futuros já mencionado. Entender quais políticas públicas ensejaram a criação desses espaços escolares poderia auxiliar no entendimento das motivações e modificações percebidas ao longo do tempo. Por fim, analisar esses museus escolares dentro da dimensão escolar e museal, ou seja, da sua dimensão formal e não formal de educação, percebendo esses espaços como um híbrido que vale ser mais conhecido.

\section{Referências}

Alves, V. M. S. (2016) Museus Escolares: de recurso de ensino ao patrimônio e a Museologia. Tese (Doutorado) em Museologia e Patrimônio Instituição de Ensino pela Universidade Federal do Estado do Rio de Janeiro, Rio de Janeiro.

Bastos, M. H. C. (2005) A Educação como espetáculo In: Stephanou,. Bastos, M.H.C. Histórias e Memórias da Educação no Brasil, Vol. II - Século XIX, Petrópolis, RJ: Editora Vozes.

Bocchi, L. A. (2013) A configuração de novos locais e práticas pedagógicas na escola: o museu escolar, os laboratórios e gabinetes de ensino do Colégio Marista Arquidiocesano de São Paulo (1908-1940). Dissertação (Mestrado) em Educação: História, Política, Pontifícia Universidade Católica de São Paulo, São Paulo.

Borcioni, L. (2012) O Museu Escolar do CEAP: reflexões sobre a prática museal e a relação entre memória e história. Dissertação (Mestrado) em Ciências Sociais, Universidade Federal de Santa Maria, Santa Maria.

ICOM (2019). Conselho Internacional de Museus. https://icom-portugal.org/2019/09/10/sobre-a-proposta-da-nova-definicao-de-museu/

Jose, V. A. S. (2020) Educação patrimonial e o Ensino de História na cidade de Santa Maria. Dissertação (Mestrado Profissional) em Patrimônio Cultural, Universidade Federal de Santa Maria, Santa Maria.

Lima, T. C. S; Mioto, R. C. T. (2007) Procedimentos metodológicos na construção do conhecimento científico: a pesquisa bibliográfica. Revista Katálysis. Florianópolis v. $10 \mathrm{n}$. esp.

Marques, M. R. (2016) Cultura Material Escolar, Patrimônio e Tecnologias: os Objetos de Ensino do Ginásio São José da Lapa - Paraná (1949-1981). (Dissertação de Mestrado Profissional em Educação e Novas Tecnologias, Centro Universitário Internacional, Curitiba).

Oliveira, F. V. (2025) Patrimônio escolar: para além da arquitetura, a materialidade do patrimônio histórico nas escolas paulistas. Tese (Doutorado) em Arquitetura e Urbanismo, Universidade De São Paulo, São Paulo.

Paz, F. R. C. (2015) Cultura Visual e Museus Escolares: representações raciais no museu Lassalista (Canoas, RS, 1925-1945). Dissertação (Mestrado) em Educação, Universidade Federal do Rio Grande Do Sul, Porto Alegre.

Peixoto, A. M. C. (2004) Museu da Escola: uma leitura em aberto. In: MENEZES, M. C. (org.) Educação, Memória e História: possibilidades e leituras. Campinas, Mercado e Letras.

Petry, M. G. (2013) Da recolha à Exposição: a constituição de museus escolares em escolas públicas primárias de Santa Catarina (Brasil - 1911-1952). Dissertação (Mestrado) em Educação, Universidade do Estado de Santa Catarina, Florianópolis.

Poggiani, A. M. L. (2011) Os museus escolares na Primeira metade do século XX: sua importância na Educação Brasileira. Dissertação (Mestrado) em Educação, Universidade Católica de Santos, Santos).

Possamai, Z. \& Paz, F. R. C. (2017) Considerações sobre Museus Escolares de Ciências, Brasil e Argentina. In: Granato, M., Ribeiro, E. S. \& Araújo, B. M. Cadernos do Patrimônio da Ciência e da Tecnologia: instituições trajetórias e Valores - Rio de Janeiro: Museu de Astronomia e Ciências Afins.

Rezende, A. C. \& Deccache-Maia, E. (2020) Museus escolares no ensino de ciência: o caso do Museu de História Natural do Instituto Superior de Educação do Rio de Janeiro. Research, Society and Development, v. 9, n. 7. DOI: http://dx.doi.org/10.33448/rsd-v9i7.3989.

Ribeiro, Q. L. F. A. (2015) Escola normal rural de juazeiro do norte: do museu vilas nova Portugal à sala de memória Amália Xavier de Oliveira. Dissertação (Mestrado) em Educação, Universidade Federal do Ceará, Fortaleza. 
Research, Society and Development, v. 10, n. 12, e540101220997, 2021

(CC BY 4.0) | ISSN 2525-3409 | DOI: http://dx.doi.org/10.33448/rsd-v10i12.20997

Santos, D. P. (2014) Prática(s) de Ensino na Escola Normal Padre Anchieta na década de 1930: o museu didático nas proposições da Professora Leontina Silva Busch. Dissertação (Mestrado) em Educação, Universidade de São Paulo, São Paulo.

Selano, A. M. F. (2016) O museu escolar e reflexões históricas: usos e apropriações da memória do Instituto de Educação Governador Roberto Silveira Dissertação (Mestrado Profissional) em Ensino de História Instituição de Ensino, Universidade do Estado do Rio De Janeiro, Rio de Janeiro.

Schelbauer, A. R. (2005) O método intuitivo e lições de coisas no Brasil no século XIX. In: Stephanou, M. \& Bastos, M.H.C. v. 2, século 19. Petrópolis: Vozes, 2005.

Schlickmann, K. S. V. (2011) Museu Irmão Luiz Gartner: Um percurso de investigação no acervo taxidermizado de aves e de mamíferos (Corupá-SC/BR 1932/1953). Dissertação (Mestrado) em Educação, Universidade do Estado De Santa Catarina, FLORIANÓPOLIS.

Silva, C. M. (2015) Museus escolares no Estado de São Paulo (1879-1942). Dissertação (Mestrado) em Educação: História, Política, Sociedade, Pontifícia Universidade Católica de São Paulo, São Paulo.

Vidal, D. G. (1999) Por uma pedagogia do olhar: os museus escolares no fim do século XIX. In: Vidal, D.G. \& Souza, M.C. C. A memória e a sombra: A escola brasileira entre o Império e a República. Belo Horizonte: Autêntica.

Witt, N. B. (2016) "Uma Joia" no Sul do Brasil, o Museu de História Natural do Colégio Anchieta: Pesquisa científica e ensino em uma escola jesuíta nas primeiras décadas do século XX (PortoAlegre/RS). Dissertação (Mestrado) em Educação, Universidade Federal do Rio Grande Do Sul, Porto Alegre. 